\title{
A study of dynamic econometric relationship between urbanization and service industries growth in China
}

\author{
Congjun Cheng \\ Hebei University (China) \\ chengcongjun@bbu.edu.cn
}

Received July 2012

Accepted October 2012

\section{Abstract:}

Purpose: The paper is going to analyze that there are dynamic quantitative relationships between Chinese urbanization and service industry.

Design/methodology/approach: According to the index number of value-added of service industry and town population/ total population ratio during the year of 1978 to 2012 in China, the paper is designed with models which are analyzed by ADF test, co-integration test, error correction model and Granger causality test, finally get the conclusion.

Findings: The paper achieves the two conclusions, one is that urbanization is the important power of service industry's growth; the other is that the level of urbanization improves the level of service industry recently.

Originality/value: Chinese urbanization and service industry have close relationship, and they also have dynamic changes. The paper studies their dynamic changes through collecting a lot of data from the year 1978 to 2010 and developing models to make quantitative analysis, for example, tables and quotations in the paper are the best proof. At last, the paper also puts forward some suggestions after get the conclusion that Chinese urbanization is the motive power to the growth of service industry.

Keywords: urbanization; service industry; co-integration test; error correction model; Granger causality test 


\section{Introduction}

The process of Chinese urbanization has become one of the major research topics among the domestic scholars and overseas scholars. "The urbanization of China" and "The high-tech of America" have been called two key factors that affect all mankind in the 21 st century by Stieglitz. What he has said also include that China's urbanization will play the lead role in regional economic growth, and will produce most important economic interests (Jiang, 2011). The tertiary industry plays a very important role to promote the economic structure optimization, improve the people's living quality, and increase chances of employment. According to Petty-Clark's law, with a corresponding increase of per capita national income, the labors will transfer to the secondary industry and other non-agricultural sectors; what's more, with the further development of the economy, the labors will transfer to the service industry. So the relationship between the service industries' development and urbanization has attracted more and more scholars' attention.

\section{Data Selection}

For the purpose of testing the dynamic relationships between urbanization and the growth of the service industry, the paper selects Chinese data the years of 1978 to 2010 for quantitative analysis. Besides, in order to eliminate the influence of population, China measures the level of the tertiary industry by the added value of per capita in it. In this thesis, the level of Chinese service industry is analyzed by the index number of value-added of the service industry. SERV refers to the level of Chinese service industry. The rate of urbanization is the ratio of town population /total population, which is the common indicator to measure the level of urbanization in the world at present and it is showed by URBA. In order to eliminate the heteroscedasticity of the data, the paper uses LN analysis on SERV and URBA, so the final data is expressed by LNURBA and LNSERV. The data is shown in Table 1.

\section{Model Development}

Firstly, the paper makes Co-integration Test between the two variables which refer to the level of urbanization and the index number of value-added of service industry. At the same time, it starts to do empirical research using time series analysis methods. Firstly, among the process of the Co-integration Test between the two variables, the first step is unit root test and determines the stationary in the two sides. Then we can conclude that whether the two variables have Co-integration relationship and further analyze the long-term equilibrium relation between them. Next, in accordance with the error-correction model, this paper tests the magnitude of the deviation between the long-term equilibrium relationship and the shortterm fluctuation between the two variables. At last, with the Granger causality test, one can 
find that whether the two variables have the short-term causal relationship or the long-term causal relationship.

\begin{tabular}{|r|r|r|r|r|}
\hline Year & \multicolumn{1}{|c|}{ SERV } & \multicolumn{1}{|c|}{ URBA } & LNSERV & LNURBA \\
\hline 1978 & 100 & 0.1792 & 4.6052 & -1.7193 \\
\hline 1979 & 107.9 & 0.1896 & 4.6812 & -1.6628 \\
\hline 1980 & 114.3 & 0.1939 & 4.7388 & -1.6404 \\
\hline 1981 & 126.2 & 0.2015 & 4.8379 & -1.6020 \\
\hline 1982 & 142.6 & 0.2113 & 4.9600 & -1.5545 \\
\hline 1983 & 164.3 & 0.2162 & 5.1017 & -1.5316 \\
\hline 1984 & 196.0 & 0.2301 & 5.2781 & -1.4692 \\
\hline 1985 & 231.7 & 0.2371 & 5.4454 & -1.4393 \\
\hline 1986 & 259.6 & 0.2452 & 5.5591 & -1.4057 \\
\hline 1987 & 296.8 & 0.2531 & 5.6931 & -1.3740 \\
\hline 1988 & 335.9 & 0.25814 & 5.8168 & -1.3543 \\
\hline 1989 & 353.9 & 0.2621 & 5.8690 & -1.3390 \\
\hline 1990 & 362.1 & 0.2641 & 5.8919 & -1.3314 \\
\hline 1991 & 394.3 & 0.2694 & 5.9771 & -1.3116 \\
\hline 1992 & 443.3 & 0.2746 & 6.0942 & -1.2924 \\
\hline 1993 & 497.4 & 0.2799 & 6.2094 & -1.2733 \\
\hline 1994 & 552.5 & 0.2851 & 6.3145 & -1.2549 \\
\hline 1995 & 606.9 & 0.2904 & 6.4084 & -1.2365 \\
\hline 1996 & 664.1 & 0.3048 & 6.4984 & -1.1881 \\
\hline 1997 & 735.3 & 0.3191 & 6.6003 & -1.1423 \\
\hline 1998 & 796.8 & 0.3335 & 6.6806 & -1.0981 \\
\hline 1999 & 871.2 & 0.3478 & 6.7699 & -1.0561 \\
\hline 2000 & 956.1 & 0.3622 & 6.8629 & -1.0156 \\
\hline 2001 & 1054.2 & 0.3766 & 6.9605 & -0.9766 \\
\hline 2002 & 1164.2 & 0.3909 & 7.0598 & -0.9393 \\
\hline 2003 & 1274.9 & 0.4053 & 7.1506 & -0.9031 \\
\hline 2004 & 1403.1 & 0.4176 & 7.2464 & -0.8732 \\
\hline 2005 & 1574.7 & 0.4299 & 7.3618 & -0.8442 \\
\hline 2006 & 1797.3 & 0.439 & 7.4940 & -0.8233 \\
\hline 2007 & 2084.6 & 0.4494 & 7.6423 & -0.7998 \\
\hline 2008 & 2301.4 & 0.4568 & 7.7413 & -0.7835 \\
\hline 2009 & 2521.5 & 0.4659 & 7.8326 & -0.7638 \\
\hline 2010 & 2762.4 & 0.4995 & 7.9239 & -0.6941 \\
\hline & & & & \\
\hline
\end{tabular}

Table 1. The level of urbanization and the index number of value-added of service industry in China (data from the years of 1978-2010, 1978=100). China Statistical Yearbook 2011 (China Statistical Yerbook, 2011)

\subsection{ADF Test}

At first, we should test whether the time series of the two variables is stationary, and whether the fallacy test exists. The purpose is to avoid the problem of "spurious regression". With the soft of Eviews6.0, the paper applies the AIC criterion to determine the optimal lag order (Li \& Song, 2011). The test style of the differential sequence will be confirmed by the corresponding principles; meanwhile, the ADF test determines whether each sequence has a unit root. Results are shown in Table 2: 


\begin{tabular}{|c|c|r|r|r|r|l|}
\hline variable & $\begin{array}{c}\text { Type of } \\
\text { test }\end{array}$ & \multicolumn{1}{|c|}{$\begin{array}{c}\text { Test } \\
\text { value }\end{array}$} & \multicolumn{2}{|c|}{$\begin{array}{r}\text { Critical value under } \\
\text { the level of }\end{array}$} & Test results \\
\hline & $(\mathrm{C}, \mathrm{T}, \mathrm{K})$ & & $1 \%$ & $5 \%$ & $10 \%$ & \\
\hline LNSERV & $(\mathrm{C}, \mathrm{T}, 3)$ & -3.7456 & -4.3098 & -3.5742 & -3.2217 & stable \\
\hline$\Delta$ LNSERV & $(\mathrm{C}, \mathrm{T}, 2)$ & -4.0282 & -4.2967 & -3.5683 & -3.2183 & stable \\
\hline LNURBA & $(\mathrm{C}, \mathrm{T}, 1)$ & -1.6139 & -4.2845 & -3.5628 & -3.2152 & unstable \\
\hline$\Delta$ LNURBA & $(\mathrm{C}, \mathrm{T}, 0)$ & -3.5723 & -4.2845 & -3.5628 & -3.2152 & stable \\
\hline
\end{tabular}

Table 2. ADF test results for each variable time series

Note: $\Delta$ in the table refers to the first order difference; among the test form $(C, T, K), C$ refers to the constant term; $T$ refers to the time trend; $K$ refers to the lag order; and they are all test equation of unit root. 0 refers to the test equation which excludes the constant term or the time trend.

Obviously, from table 2, we can conclude that the ADF test value of the value-added of service industry is -3.7456 , and it is stationary at $5 \%$ and $10 \%$. The ADF test value of urbanization is 1.613985 , and it is greater than the critical value which at the level of significance, so it is the non-stationary unit root. After that, through the integration test on the two variables' first order difference, we will discover a fact that the ADF test value in the two valuables' first order difference sequence are -4.0282 and -3.5723 , and they are both stationary at the level of $5 \%$ and $10 \%$, so it shows a fact that the two variables' first order difference are both stationary.

\subsection{Co-integration Test}

To further analyze the long-term equilibrium relation between urbanization and the development of service industry, the paper makes co-integration test for the two variables. Through the above analysis, it finds that the sequences of the two variables LNURBA and LNSERV meet the premise of the co-integration test, so one can consider that whether cointegration relationship exists in them (Wang, 2008). Now, with Engle-Granger test (two-step testing method), we can make co-integration test between LNSERV and LNURBA.

First step, using OLS method estimate the long-term equilibrium equation

$$
\text { LNSERV }_{t}=10.30177+3.341910 \text { LNURBA }_{t}
$$

Calculating the non-equilibrium error of the ordinary least-squares estimation, it will get the sequence:

$$
\varepsilon_{t}=-3.341910 L N U R B A_{t}+L N S E R V_{t}-10.30177
$$

Second step, one should test whether the residuals $\varepsilon_{\mathrm{t}}$ of the above models are stable sequences, and make unit root test to the estimated residuals $\varepsilon_{t}$ of the above-mentioned regressive equations. The absolute value of the ADF test statistic is -2.000870 , and it is 
greater than the absolute value of the critical value when the level of significance at $5 \%, 10 \%$. Therefore, the estimated residuals sequence $\varepsilon_{\mathrm{t}}$ is stationary sequence. So it indicates that cointegration relationship exists in LNURBA and LNSERV. It is shown in table 3:

\begin{tabular}{|c|c|c|r|c|c|c|c|}
\hline variable & Type of test & $\begin{array}{c}\text { ADF test } \\
\text { value }\end{array}$ & $\begin{array}{c}\text { Level of } \\
\text { significance }\end{array}$ & $\begin{array}{c}\text { Critical } \\
\text { value }\end{array}$ & AIC & DW & $\begin{array}{c}\text { Test } \\
\text { result }\end{array}$ \\
\hline & & & $1 \%$ & -2.6416 & & & \\
\hline$\varepsilon_{\mathrm{t}}$ & $(0,0,1)$ & -2.0452 & $5 \%$ & -1.9520 & -3.3068 & 1.8714 & stable \\
\hline & & & $10 \%$ & -1.6104 & & & \\
\hline
\end{tabular}

Table 3. The stationary test of residuals $\varepsilon_{\mathrm{t}}$

Note: among the test form $(\mathrm{C}, \mathrm{T}, \mathrm{K}), \mathrm{C}$ refers to the constant term; $\mathrm{T}$ refers to the time trend; $\mathrm{K}$ refers to the lag order; and they are all test equation of unit root. 0 refers to the test equation which excludes the constant term or the time trend.

From the co-integration model, it concludes that the level of urbanization and the growth of the service industry have a positive correlation, and once the urbanization changes $1 \%$ each time; it will make the proportion of the service industries' production value increasing to $3.3419 \%$. From the table 3, it concludes that the absolute value of residual $\varepsilon t^{\prime}$ ADF test is 2.0452, and it is greater than the absolute value of the critical value when the level of significance at $10 \%, 5 \%$, so the co-integration regression equation has a practical significance.

\subsection{Error Correction Model}

The error correction model is the econometric model which has a particular form. According to Engel-Granger theorem, if the co-integration relationship exists in a set of variables, their short-term non-equilibrium relationship will always has an error correction model, which means that the co-integration regression always can be converted to the error correction model. Besides, according to Granger theorem and results of the two variables' unit root test and the co-integration test, we can express the error correction model of the short-term dynamic equilibrium relationship between the urbanization and the index number of valueadded of tertiary industry (Wang, 2008). It is:

$$
\Delta L N S E R V_{t}=\Delta L N U R B A-0.120468 \Delta L N S E R V_{t-1}+0.489958 \Delta L N U R B A_{t}-0.035226 e \mathrm{~cm}_{t-1}
$$

On the basis of the error correction model, we find that the two variables' short-term dynamic equilibrium relationship refers to that once the urbanization level changes 1 unit each time, the proportion of the service industries' output value will change 0.257279 units in the same direction. In addition, the value is smaller than regression coefficients in the long-term cointegration regression equation, so it indicates that the long-term impact which refers to the development of urbanization on the proportion of the service industries' output value is more significant than the shot-term impact. 


\subsection{Granger Causality Test}

We should make the Grange causality test between the level of urbanization and the development of the service industry by OLS, and the maximum lag order is 5 . The basic approaches are: first, to estimate the degree of explanation, of which refers to how the current LNSERV is explained by its value of lag phase, second, to test whether the lag order that introduce the sequence LNUBRA has improved significantly the interpreted degree of LNSERV (Li \& Song, 2011). Results in table 4:

\begin{tabular}{|c|r|r|l|l|}
\hline Granger causality & Lag length & F-value & P-value & Results \\
\hline LNSERV can not cause LNURBA & 1 & 0.01717 & 0.8966 & Accept \\
\hline LNURBA can not cause LNSERV & 1 & 5.19375 & 0.0302 & Refuse \\
\hline LNSERV can not cause LNURBA & 2 & 0.18469 & 0.8324 & Accept \\
\hline LNURBA can not cause LNSERV & 2 & 1.76908 & 0.1904 & Accept \\
\hline LNSERV can not cause LNURBA & 3 & 0.84537 & 0.4832 & Accept \\
\hline LNURBA can not cause LNSERV & 3 & 1.39792 & 0.2687 & Accept \\
\hline LNSERV can not cause LNURBA & 4 & 1.58781 & 0.2163 & Accept \\
\hline LNURBA can not cause LNSERV & 4 & 0.88449 & 0.4910 & Accept \\
\hline LNSERV can not cause LNURBA & 5 & 1.47102 & 0.2506 & Accept \\
\hline LNURBA can not cause LNSERV & 5 & 1.47750 & 0.2486 & Accept \\
\hline
\end{tabular}

Table 4. Granger causality test between various variables

Therefore, in lag phase 1, the level of urbanization cause the service industry's development, but the latter can not cause of the former. In lag phase2, lag phase 3, lag phase 4 and lag phase 5, the two sides have non-Granger causality (Li \& Song, 2011). From the above, we can conclude that the level of urbanization and the development of service industry have Granger causality recently, but the effect maybe one-way, which means that the improvement of urbanization level promotes the development of service industry. In the long-term perspective, the mutual influences of urbanization and service industry have non-Granger causality.

\section{Conclusions and Suggestions}

According to Chinese data in the year of 1987-2010, we make ADF unit root test, cointegration test, error correction model test, vector auto regression analysis and Granger causality test between urbanization level and the index number of value-added of service industry in China, so the conclusions can be drown:

From the co-integration equation, we can find that the equation fitting very well and the coefficients are more significance; from the co-integration model, the level of urbanization and the development of service industry have the positive correlation; finally, we conclude that the level of urbanization promotes the development of service industry, in other words, urbanization is the power of promoting the growth of service industry. 
From the causality analysis, the level of urbanization and the development of service industry have the Granger causality recently, but the effect is one-way, which refers to only the level of urbanization promotes the development of service industry. In the long-term perspective, the mutual influences of urbanization and service industry have non-Granger causality.

Finally, urbanization will lead to changes in the structure of population, and cause the movement of population. That is to say, urbanization provides the supply of labor forces to the growth of service industry, and changes in employment structure, so it ultimately promotes the development of service industry (Yang \& Yang, 2010).

According to the research and the conditions of the service industry's development, we can get the following suggestions.

We should optimize the industrial structure to promote the development of the service industry (Gao, 2010). Contorted structure of industry is the germ that causes inconformity between urbanization and the development of service industry. Bidirectional guides are taken to quicken the urbanization courses and promote the development of service industry. From economy development practices, urbanization is the only way which we must pass. Therefore, we need to constantly adjust the industrial structure, strength the development of the service industry, and change the dominant status of the heavy industry. Thus, it helps the rural surplus labor forces changing to non-agriculture forces and realizes the transformation of urbanization, promotes the urbanization process of China.

We should eliminate the barrier of urbanization and fully achieve the benign and synergistic relationship between the urbanization and the service industry. In cities, the number of the migrant labor is gradually increased and they make great contribution to the economic development. In rural areas, the government should reinforce the job training to improve the quality of peasants and explode the discrimination of employment and policy which exists in the labor market (Gao, 2010). With the flowing of the rural surplus labor, the government should set about reform from every aspect such as employment, education, medical care, and social insurance, protecting the legal right of the migrant labors, thus we will achieve the scientific city management. Therefore, we should improve the household, employment and social insurance system and eliminate the barrier between urban and rural areas. In this way, it can stimulate the development of service industry and in return of driving further the speed of the urbanization process.

We should improve the environment for urbanization and the coordination of the service industry. Reasonable and appropriate size of city system provide a stage for the development of the service industry, and gradually forms urban agglomerations or metropolitan area on the basis of major cities, thus it boosts the size and structural adjustment of the modern service industry. Similarly, we should also enrich the development level of service industry and 
develop the new raised service industry intensively so as to change the elements and the economic structure of cities, gain new vigor and power for the development of the urbanization. From the macroscopic view, if the government puts more input on urbanization and the service industry; it will promote mutual development between them.

We should adjust and improve the mechanism of the job market, and guide the labor entering the service industry, thus employment structure will get the adjustment. Service industry is an elastic industry which has a high employment rate and a stronger capacity of absorbing the labor; moreover, raising the level of economic development will continue to play a driving effect towards overall employment. The structural change of the urban employment will also dramatically increase the level of the urban employment and the quality of employment. Moreover, the increase of the consumer demand will also put forward higher demand for the service industry which refers to improve the quality of living standards as well as the other related industry; it will be the long-term power of service industry's development.

\section{References}

Gao, L.B. (2010). Quantitative Analysis and Suggestions between Service Industry and Urbanization in Jilin Province. Contemporary Economics, 13, 86-87.

Jiang, X.J. (2011). The Growth of Service industry: the True Meaning, the Multiple Effects and Future Development. Economic Research Journal, 4, 4-14.

Li, C.L. \& Song, T.H. (2010). Correlative Analysis between Service Industry and Urbanization in Shandong Province. Economic Research Guide, 1, 143-144.

Wang, Y. (2008). Analysis of Applied Time Series. Beijing: China Renmin University Press.

Yang, S.G. \& Yang, J.M. (2010). The Relationship between Urbanization and Tertiary IndustryAn Empirical Analysis Based on Hunan Province. Commercial Research, 3,143-147.

Journal of Industrial Engineering and Management, 2013 (www.jiem.org)

El artículo está con Reconocimiento-NoComercial 3.0 de Creative Commons. Puede copiarlo, distribuirlo y comunicarlo públicamente siempre que cite a su autor y a Intangible Capital. No lo utilice para fines comerciales. La licencia completa se puede consultar en http://creativecommons.org/licenses/by-nc/3.0/es/ 